\title{
Actual compliance rate of Enhanced Recovery After Surgery protocol in laparoscopic distal gastrectomy
}

\author{
Sang Hyeok Park ${ }^{1}$, So Hyun Kang ${ }^{1}$, Sang Jun Lee ${ }^{1}$, Yongjoon Won ${ }^{1}$, Young Suk Park ${ }^{1,3}$, Sang-Hoon Ahn ${ }^{1,3}$, Yun-Suhk Suh ${ }^{1,3}$, \\ Do Joong Park ${ }^{2,3}$, Hyung-Ho Kim ${ }^{1,3}$ \\ ${ }^{1}$ Department of Surgery, Seoul National University Bundang Hospital, Seongnam, Korea \\ 2Department of Surgery, Seoul National University Hospital, Seoul, Korea \\ ${ }^{3}$ Department of Surgery, Seoul National University College of Medicine, Seoul, Korea
}

Purpose: The Enhanced Recovery After Surgery (ERAS) protocol enhances recovery rate after laparoscopic distal gastrectomy (LDG). An ERAS protocol has been applied to most patients who underwent LDG at our center. In this study, we determined the actual compliance rate of the ERAS protocol and analyzed the risk factors for noncompliance.

Methods: Medical records of 1,013 patients who underwent LDG from March 2016 to December 2017 were reviewed retrospectively. The compliance group (A) included 327 patients who were discharged within four days postoperatively. The noncompliance group (B) comprised 686 patients who were not discharged within four days postoperatively.

Results: The compliance rate of the ERAS protocol was 32.3\%. Potential compliance rate was $53.2 \%$. Most common reasons for noncompliance were fever $(n=115)$ and ileus $(n=111)$. The 30-day emergency room visit rate was significantly lower in group A than that in group B $(p=0.006)$. Median age, American Society of Anesthesiologists (ASA) physical status classification, operation time, and pathologic stage were significantly higher in group B than those in group A $(p<0.001, p<0.001, p=0.005$, and $p<0.001$, respectively). Risk factors for noncompliance were ASA classification of $\geq \mathrm{III}$ (odds ratio [OR], 2.251; $p=$ 0.007 ), age of $\geq 70$ years (OR, 1.572; $p=0.004)$, operation time of $\geq 180$ minutes (OR, $1.475 ; p=0.003$ ), and pathologic stage of $\geq \operatorname{III}(\mathrm{OR}, 2.224 ; p<0.001)$.

Conclusion: The current ERAS protocols should be applied to patients without risk factors.
Received August 26, 2021

Revised October 28, 2021

Accepted October 30, 2021

Corresponding author

Sang-Hoon Ahn

Department of Surgery, Seoul

National University Bundang

Hospital, Seoul National University

College of Medicine, 82 Gumi-ro

173beon-gil, Bundang-gu, Seongnam

13620 , Korea

Tel: $+82-31-787-7106$

Fax: $+82-31-787-4078$

E-mail: viscaria@snubh.org

ORCID:

https://orcid.org/0000-0001-8827-3625

Keywords: Laparoscopy, Stomach neoplasms, Gastrectomy, Enhanced Recovery After Surgery, Compliance

This is an Open Access article distributed under the terms of the Creative Commons Attribution Non-Commercial License (http:/ creativecommons.org/licenses/by-nc/4.0/) which permits unrestricted non-commercial use, distribution, and reproduction in any medium, provided the original work is properly cited.
Copyright $\odot$ The Korean Society of Endoscopic and Laparoscopic Surgeons.

\section{INTRODUCTION}

According to several studies, laparoscopic gastric cancer surgery and open surgery are equally safe and effective; however, laparoscopic gastric cancer surgery has many advantages such as low operative pain, small blood loss, and short postoperative hospital stay over open surgery [1-3]. Therefore, laparoscopic gastrectomy has largely replaced open surgery for the treatment of gastric cancer. In order to maximize the advantages of laparoscopic gastrectomy, the application of Enhanced Recovery After Surgery (ERAS) protocols after gastric cancer surgery is increasing [4-7].

ERAS protocol is a multidisciplinary perioperative care offered for minimizing postoperative stress and accelerating recovery [8]. It includes minimal preoperative fasting, early oral intake, and 
early ambulation. ERAS protocols reportedly improve postoperative recovery in many abdominal surgeries, especially in colorectal surgery $[9,10]$.

However, not enough studies have assessed the application of the ERAS protocols for gastric cancer. Therefore, our institute performed a prospective randomized control trial and reported that the ERAS protocol significantly improves recovery time in laparoscopic distal gastrectomy (LDG) patients without significantly affecting complications, readmission, and mortality [11].

Based on the previous results, our center has applied ERAS protocol to the most LDG patients since March 2016. In this study, we aimed to determine the actual compliance rate of the ERAS protocol and identify the risk factors for noncompliance with the ERAS protocol.

\section{MATERIALS AND METHODS}

\section{Patient selection}

Gastric cancer patients who underwent LDG from March 2016 to December 2017 in single center (Seoul National University Bundang Hospital) were included. Cases of synchronous malignancy and cases of conversion to open or combined resection of other organs were excluded. A total of 1,013 patients were included in this study.

\section{Surgical procedures}

Surgeries were performed by four surgeons in a single center. Totally LDG with D1+ or D2 lymph node dissection was performed. Billroth I, Billroth II, and Roux en Y reconstructions were performed in 72 (7.1\%), 378 (37.3\%), and 563 cases (55.6\%), respectively.

\section{ERAS protocol in our institute}

The ERAS protocol used in this study is almost similar to the one used by Kang et al. [11], except that our protocol routinely uses intravenous (IV) patient-controlled analgesia (PCA) instead of epidural PCA (Table 1). Before admission, operative risk was assessed, and patients received preoperative education. After admission, oral carbohydrate solution intake was allowed until 2 hours before surgery. Bowel preparation was not carried out. Patients started taking sips of water on postoperative day (POD) 1. If tolerated, the diet was progressed in the order; semifluid diet, followed by semi-blended diet each day. The IV PCA was removed on POD 2. Patients who met the discharge criteria on POD 4 were discharged. The discharge criteria were as follows: (1) tolerance to soft blended diet for 24 hours, (2) safe ambulation of $600 \mathrm{~m}$ without assistance, (3) no requirement for additional oral
Table 1. Enhanced Recovery After Surgery protocol used in our institute

\begin{tabular}{|c|c|}
\hline Time & Protocols \\
\hline $\begin{array}{r}\text { Days before } \\
\text { admission }\end{array}$ & $\begin{array}{l}\text { Preoperative education } \\
\text { (including videos on smartphones) } \\
\text { Operative risk assessment }\end{array}$ \\
\hline Preoperative days & $\begin{array}{l}\text { Counseling for patient and family } \\
\text { Written informed consent } \\
\text { No bowel preparation } \\
\text { Oral carbohydrate solution intake up to } 2 \mathrm{hr} \\
\text { before surgery }\end{array}$ \\
\hline Day of surgery & $\begin{array}{l}\text { Insertion of a Foley catheter } \\
\text { No Nasogastric tube insertion } \\
\text { IV PCA } \\
\text { Routine use of closed drain } \\
\left.\mathrm{O}_{2} \text { inhalation ( } 3 \mathrm{~L} / \mathrm{min}\right)\end{array}$ \\
\hline POD 1 & $\begin{array}{l}\text { Use of routine antiemetics } \\
\text { Sips of water, if tolerated } \\
\text { IV PCA } \\
\text { Removal of Foley catheter in the morning } \\
\left.\mathrm{O}_{2} \text { inhalation ( } 3 \mathrm{~L} / \mathrm{min}\right) \\
\text { Encouragement of ambulation }\end{array}$ \\
\hline POD 2 & $\begin{array}{l}\text { Semifluid diet, if tolerated } \\
\text { Removal of IV PCA and use of oral analgesics } \\
\text { Laboratory blood test } \\
\text { Drain removal }\end{array}$ \\
\hline POD 3 & Soft blended diet, if tolerated \\
\hline POD 4 & Discharge, if the patient met the discharge criteriaa) \\
\hline
\end{tabular}

IV, intravenous; PCA, patient-controlled analgesia; POD, postoperative day. ${ }^{a}$ Discharge criteria: (1) tolerance to soft blended diet for 24 hours, (2) safe ambulation of $600 \mathrm{~m}$ without assistance, (3) no requirement for additional oral or IV analgesics after cessation of PCA, and (4) afebrile status (an axillary temperature of less than $37.2^{\circ} \mathrm{C}$ ) without major complications.

or IV analgesics after cessation of PCA, and (4) afebrile status (an axillary temperature of less than $37.2^{\circ} \mathrm{C}$ ) without major complications [11].

\section{Study design}

Patients who were discharged within 4 days after surgery were defined as the compliance group (group A), and patients who were not discharged within 4 days after surgery for any reason were defined as the noncompliance group (group B).

The primary endpoint of this study was the rate of compliance group among all patients (compliance rate). The secondary endpoints of this study were 30-day readmission rate and emergency room (ER) visit rate in each group. Additionally, the risk factors for noncompliance with the ERAS protocol were analyzed. 


\section{Data collection and analysis}

Data were collected in our electronic medical record database and reviewed retrospectively. Statistical analyses were performed using IBM SPSS version 22.0 (IBM Corp., Armonk, NY, USA). The chi-square test and $t$ test were conducted to analyze categorical variables and continuous variables, respectively. Logistic regression analysis was performed for multivariate analysis.

\section{RESULTS}

\section{Patients' characteristics}

The median age was 58.70 years in group A and 62.27 years in group $B$. The mean age was significantly lower in group A than that in group $B(p<0.001)$. Group A showed significantly shorter operation time than group B (164.61 minutes vs. 174.13 minutes, $p$ $=0.005$ ). The proportion of patients with an American Society of Anesthesiologists (ASA) physical status (PS) classification of III

Table 2. Patients' characteristics

\begin{tabular}{|c|c|c|c|}
\hline Characteristic & Group A & Group B & $p$ value \\
\hline No. of patients & 327 & 686 & \\
\hline Age (yr) & $58.70 \pm 11.51$ & $62.27 \pm 12.06$ & $<0.001$ \\
\hline Sex & & & 0.349 \\
\hline Male & $213(65.1)$ & $426(62.1)$ & \\
\hline Female & $114(34.9)$ & $260(37.9)$ & \\
\hline Body mass index $\left(\mathrm{kg} / \mathrm{m}^{2}\right)$ & $23.84 \pm 3.02$ & $24.15 \pm 3.27$ & 0.167 \\
\hline Previous abdominal surgery & $69(21.1)$ & $124(18.1)$ & 0.252 \\
\hline Operation time (min) & $164.61 \pm 50.90$ & $174.13 \pm 50.65$ & 0.005 \\
\hline ASA PS classification & & & $<0.001$ \\
\hline I & $151(46.2)$ & $246(35.9)$ & \\
\hline$\|$ & $168(51.4)$ & $383(55.8)$ & \\
\hline II & $8(2.4)$ & $55(8.0)$ & \\
\hline IV & $0(0)$ & $2(0.3)$ & \\
\hline Early complications & $9(2.8)$ & $50(7.3)$ & 0.004 \\
\hline Blood loss (ml) & $31.42 \pm 49.288$ & $36.48 \pm 61.987$ & 0.162 \\
\hline Extent of LND & & & 0.602 \\
\hline D1+ & $212(64.8)$ & $430(62.7)$ & \\
\hline D2 & $115(35.2)$ & $256(37.3)$ & \\
\hline cT staging & & & $<0.001$ \\
\hline cTx & $129(39.5)$ & $272(39.7)$ & \\
\hline cT1 & $118(36.1)$ & $162(23.6)$ & \\
\hline cT2 & $33(10.1)$ & $67(9.8)$ & \\
\hline cT3 & $37(11.3)$ & 113 (16.5) & \\
\hline cT4 & $7(2.1)$ & $52(7.6)$ & \\
\hline cN staging & & & 0.003 \\
\hline cNO & $307(93.9)$ & $590(86.0)$ & \\
\hline $\mathrm{cN} 1$ & $14(4.3)$ & $38(5.5)$ & \\
\hline $\mathrm{cN} 2$ & $1(0.3)$ & $18(2.6)$ & \\
\hline cN3 & $2(0.6)$ & $20(2.9)$ & \\
\hline
\end{tabular}


Table 2. Continued

\begin{tabular}{lccc}
\hline \multicolumn{1}{c}{ Characteristic } & Group A & Group B & $p$ value \\
\hline Postoperative TNM staging & & & $<0.001$ \\
IA & $212(64.8)$ & $390(56.9)$ & \\
IB & $44(13.5)$ & $71(10.3)$ & \\
IIA & $18(5.5)$ & $45(6.6)$ & \\
IIB & $17(5.2)$ & $37(5.4)$ & \\
IIIA & $9(2.8)$ & $39(5.7)$ & \\
IIIB & $7(2.1)$ & $32(4.7)$ & \\
IIIC & $3(0.9)$ & $91(4.5)$ & \\
IV & $0(0)$ & $31(4.3)$ & \\
No residual tumor (after ESD) & $17(5.2)$ & & \\
\hline
\end{tabular}

Values are presented as mean \pm standard deviation or number (\%).

ASA, American Society of Anesthesiologists; PS, physical status; LND, lymph node dissection; c, clinical; ESD, endoscopic submucosal dissection.

Group A, compliance group; Group B, noncompliance group.

or IV was significantly greater in group B than that in group A ( $p$ $<0.001$ ). Moreover, clinical (c) stage and postoperative pathologic stage were significantly higher in group $B$ than those in group A (cT, $p<0.001$; $\mathrm{cN}, p=0.003$; postoperative pathologic stage, $p$ $<0.001)$. Sex, body mass index, history of previous abdominal operation, estimated blood loss, and extent of lymph node dissection showed no significant differences between the groups (Table 2).

\section{Compliance rate}

Group A included 327 patients. Therefore, the actual compliance rate of the ERAS protocol in patients who underwent LDG was $32.3 \%$ (327 of 1,013). Potential compliance rate, including 212 patients without postoperative medical problems in group B, was $53.2 \%$ (539 of 1,013).

There was no significant difference in 30-day readmission rate between groups A and B (3.7\% vs. 5.1\%). Group A showed significantly lower 30-day ER visit (without readmission) rate than group B ( $1.2 \%$ vs. $4.7 \%, p=0.006)$.

\section{Reasons for delayed discharge}

In 686 patients, discharge was delayed. Among them, 212 patients had no medical reasons for delayed discharge. The most common medical reason for delayed discharge was fever without a focus of infection ( $\mathrm{n}=115,11.4 \%)$, followed by ileus ( $\mathrm{n}=111,11.0 \%)$, intraoperative events $(n=38,3.8 \%)$, underlying diseases $(n=31$, 3.1\%), postprandial discomfort $(n=28,2.8 \%)$, and others (Table 3).
Table 3. Causes for noncompliance with the Enhanced Recovery After Surgery protocol

\begin{tabular}{|lc|}
\hline \multicolumn{1}{c}{ Cause } & Data \\
\hline Unknown (without medical problem) & $109(10.8)$ \\
\hline Patient's demand (without medical problem) & $103(10.2)$ \\
\hline Fever (without a focus of infection) & $115(11.4)$ \\
\hline lleus & $111(11.0)$ \\
\hline Intraoperative event/findings & $38(3.8)$ \\
\hline Underlying diseases & $31(3.1)$ \\
\hline Postprandial discomfort (no ileus or delayed gastric emptying) & $28(2.8)$ \\
\hline Atelectasis & $19(1.9)$ \\
\hline Pneumonia & $17(1.7)$ \\
\hline Drain related problems & $16(1.6)$ \\
\hline Lab abnormalities & $15(1.5)$ \\
\hline Postoperative pain & $15(1.5)$ \\
\hline Postoperative bleeding & $11(1.1)$ \\
\hline Delayed gastric emptying & $8(0.8)$ \\
\hline Fluid collection & $7(0.7)$ \\
\hline Anastomosis or duodenal stump leakage & $4(0.4)$ \\
\hline Others & $39(3.9)$ \\
\hline
\end{tabular}

Values are presented as number (\%).

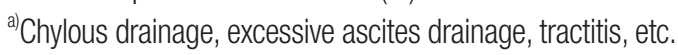

\section{Risk factor analysis}

In univariate analysis, hypertension (odds ratio [OR], 1.493; $p=$ 
Table 4. Analysis of the risk factors for noncompliance with the Enhanced Recovery After Surgery protocol

\begin{tabular}{|c|c|c|c|c|}
\hline \multirow{2}{*}{ Risk factor } & \multicolumn{2}{|c|}{ Univariate analysis } & \multicolumn{2}{|c|}{ Multivariate analysis } \\
\hline & $\mathrm{OR}(95 \% \mathrm{Cl})$ & $p$ value & $\mathrm{OR}(95 \% \mathrm{Cl})$ & $p$ value \\
\hline \multicolumn{5}{|l|}{ Underlying disease } \\
\hline Hypertension & $1.493(1.106-2.014)$ & 0.009 & $1.140(0.852-1.525)$ & 0.378 \\
\hline Diabetes mellitus & $1.680(1.128-2.503)$ & 0.010 & $1.245(0.857-1.809)$ & 0.250 \\
\hline Cardiac & 2.218 (1.072-4.590) & 0.028 & $1.583(0.794-3.156)$ & 0.192 \\
\hline Cerebral & $2.105(0.757-5.849)$ & 0.145 & $1.125(0.472-2.682)$ & 0.790 \\
\hline Pulmonary & $0.985(0.553-1.752)$ & 0.958 & $0.953(0.553-1.643)$ & 0.863 \\
\hline Renal & 1.402 (0.709-2.770) & 0.329 & $0.403(0.040-4.038)$ & 0.440 \\
\hline Hepatic & $1.765(0.863-3.727)$ & 0.132 & $5.662(0.515-62.233)$ & 0.156 \\
\hline Age, $\geq 70$ yr & $1.823(1.325-2.510)$ & $<0.001$ & $1.572(1.158-2.135)$ & 0.004 \\
\hline ASA PS classification, $\geq 111$ & $4.286(1.995-9.207)$ & $<0.001$ & $2.251(1.245-4.070)$ & 0.007 \\
\hline Operation time, $\geq 180 \mathrm{~min}$ & $1.494(1.165-1.916)$ & 0.002 & $1.475(1.137-1.914)$ & 0.003 \\
\hline Postoperative stage, $\geq 3$ & 2.595 (1.759-3.828) & $<0.001$ & $2.224(1.488-3.324)$ & $<0.001$ \\
\hline
\end{tabular}

ASA, American Society of Anesthesiologists; PS, physical status.

0.009 ), diabetes (OR, $1.680 ; p=0.010)$, cardiac disease (OR, 2.218; $p$ $=0.028$ ), old age (OR, 1.831; $p<0.001)$, high ASA PS classification (OR, 4.286; $p<0.001)$, long operation time (OR, 1.494; $p=0.003)$, and advanced postoperative pathologic stage (OR, 2.595; $p<$ 0.001 ) showed significantly higher odds ratio (Table 4 ). However, in multivariate analysis, old age (OR, 1.572; $p=0.004)$, high ASA PS classification (OR, 2.251; $p=0.007$ ), long operation time (OR, $1.475 ; p=0.003$ ), and advanced postoperative pathologic stage $(\mathrm{OR}, 2.224 ; p<0.001)$ showed significantly higher odds ratio (Table 4).

\section{DISCUSSION}

The actual compliance rate of the ERAS protocol was $32.3 \%$. However, group B contained many patients without postoperative medical problems $(n=212)$, who could have potentially been in group A. After including these patients, potential compliance rate of the ERAS protocol was $53.2 \%$. In a study of 290 patients with gastric cancer, Gianotti et al. [12] reported that the postoperative compliance of the ERAS protocol was $82.5 \%$, and the median achievement of discharge criteria was 7 days after surgery. The compliance rate in our study was much lower than that reported by Gianotti et al. [12]. However, in our study, all cases that did not be discharged on POD 4 were defined as noncompliance, and more than $80 \%$ of all patients satisfied the discharge criteria and were actually discharged within POD 7. Therefore, it cannot be accepted as an inferior result. Nevertheless, setting the discharge date as POD 4 is considered to be rather strict, so we plan to readjust the discharge time of the ERAS protocol.
The proportion of patients with nonmedical reasons for delayed discharge was very high $(n=212,20.9 \%)$. It may be due to the low burden of medical expenses for patients as the National Health Insurance of South Korea covers a large portion of medical expenses for cancer patients. Several studies have reported that insurance status actually affects hospital length of stay [13-15].

The most common medical reason for delayed discharge was fever without a focus of infection $(\mathrm{n}=115,11.4 \%)$. Therefore, if infection is excluded through careful physical examination, laboratory test, and imaging evaluation, patients without significant comorbidity could be discharged with short-term outpatient follow-up care $[16,17]$. The second most common reason for noncompliance was postoperative ileus $(n=111,11.0 \%)$. Liang et al. [18] reported that the proportion of patients with ileus after laparoscopic gastrectomy was $14.14 \%$. Huang et al. [19] reported ileus after laparoscopic gastrectomy in $18.52 \%$ of patients. Our study reported a lower rate of postoperative ileus than those studies. Furthermore, both the studies reported that postoperative pathologic stage and age were higher in the postoperative ileus group. These are similar factors of noncompliance group in our study. If the stage is high, the operation is difficult and lengthy, and the time for tissue or intestinal manipulation is long. As a result, it is expected that the inflammatory response or decreased intestinal motility after surgery is more severe. These factors are thought to increase the likelihood of noncompliance $[18,19]$.

Many studies have reported that the compliance with ERAS protocols is poor in elderly patients or patients with comorbidity $[20,21]$. Similarly, in this study, the compliance with the ERAS 
protocol was lower in elderly patients and patients with comorbidity. However, previous studies have recommended the careful application of ERAS protocols even in elderly patients because of the clear benefits of ERAS protocols [20,21]. Therefore, new modified protocols should be applied to these patients. However, since 30-day readmission and ER visit rate were not high in both the groups, the existing protocols could be safely applied to patients without risk factors.

In a previous randomized controlled trial, Kang et al. [11] applied epidural PCA in the ERAS group. However, epidural PCA requires an additional invasive procedure for epidural catheter insertion before surgery, and there were inconveniences such as unexpected removal of the epidural catheter. Therefore, our ERAS protocol uses IV PCA instead of epidural PCA. It seems that IV PCA can replace epidural PCA because the proportion of delayed discharge caused by postoperative pain is quite low $(\mathrm{n}=$ $15,1.5 \%)$.

We determined the actual compliance rate of the ERAS protocol in a large volume of patients with gastric cancer who underwent LDG and showed that the application of the ERAS protocol should be modified according to patient characteristics. This is an advantage of this study. As this study was retrospective in nature and assessed medical records, there were limitations in interpretation as there were many cases in which delay-causing factors in discharge were omitted or not described in detail. Additionally, this study did not include a new ERAS protocol applicable to patients with risk factors. Therefore, additional research is needed to establish a new ERAS protocol for patients with risk factors.

In conclusion, the compliance rate of the ERAS protocol in LDG patients was lower in patients with old age, high ASA PS classification, and advanced disease. Therefore, the ERAS protocol used in this study can be selectively applied to patients. Further research is needed to develop a modified ERAS protocol for patients with risk factors.

\section{NOTES}

\section{Ethical statements}

We conducted this study in compliance with the principles of the Declaration of Helsinki. The protocol used in this study was reviewed and approved by the Institutional Review Board of Seoul National University Bundang Hospital (No. B-2109-707-104). Since this study is a retrospective study that reviewed electronic charts, formal consent from the patients was waived.

\section{Authors' contributions}

Conceptualization, Formal analysis, Methodology, Visualization:
SHP, SHA

Data curation: SHP, SHK, SJL, YJW

Investigation: All authors

Project administration: SHA, HHK

Writing-original draft: SHP

Writing-review \& editing: SHP, SHA, YSS, DJP, HHK

All authors read and approved the final manuscript.

\section{Conflict of interest}

All authors have no conflicts of interest to declare.

\section{Funding/support}

This research was funded by a research grant from Seoul National University Bundang Hospital (SNUBH-14-2016-0008).

\section{ORCID}

Sang Hyeok Park, https://orcid.org/0000-0002-9725-0465

So Hyun Kang, https://orcid.org/0000-0002-8248-9043

Sang Jun Lee, https://orcid.org/0000-0001-9498-0254

Yongjoon Won, https://orcid.org/0000-0001-9222-288X

Young Suk Park, https://orcid.org/0000-0002-6352-9759

Sang-Hoon Ahn, https://orcid.org/0000-0001-8827-3625

Yun-Suhk Suh, https://orcid.org/0000-0003-3319-8482

Do Joong Park, https://orcid.org/0000-0001-9644-6127

Hyung-Ho Kim, https://orcid.org/0000-0002-8916-0048

\section{REFERENCES}

1. Kim W, Kim HH, Han SU, et al. Decreased morbidity of laparoscopic distal gastrectomy compared with open distal gastrectomy for stage I gastric cancer: short-term outcomes from a multicenter randomized controlled trial (KLASS-01). Ann Surg 2016;263:28-35.

2. Hyung WJ, Yang HK, Park YK, et al. Long-term outcomes of laparoscopic distal gastrectomy for locally advanced gastric cancer: the KLASS-02-RCT randomized clinical trial. J Clin Oncol 2020;38:33043313.

3. Kim HH, Han SU, Kim MC, et al. Effect of laparoscopic distal gastrectomy vs open distal gastrectomy on long-term survival among patients with stage I gastric cancer: the KLASS-01 randomized clinical trial. JAMA Oncol 2019;5:506-513.

4. Aoyama T, Yoshikawa T, Sato T, et al. Equivalent feasibility and safety of perioperative care by ERAS in open and laparoscopy-assisted distal gastrectomy for gastric cancer: a single-institution ancillary study using the patient cohort enrolled in the JCOG0912 phase III trial. Gastric Cancer 2019;22:617-623.

5. Mortensen K, Nilsson M, Slim K, et al. Consensus guidelines for enhanced recovery after gastrectomy: Enhanced Recovery After 
Surgery $\left(\right.$ ERAS $\left.^{\circledR}\right)$ Society recommendations. Br J Surg 2014;101:12091229.

6. Kim JW, Kim WS, Cheong JH, Hyung WJ, Choi SH, Noh SH. Safety and efficacy of fast-track surgery in laparoscopic distal gastrectomy for gastric cancer: a randomized clinical trial. World J Surg 2012;36:2879-2887.

7. Ikeda O, Sakaguchi Y, Aoki Y, et al. Advantages of totally laparoscopic distal gastrectomy over laparoscopically assisted distal gastrectomy for gastric cancer. Surg Endosc 2009;23:2374-2379.

8. Ljungqvist $\mathrm{O}$, Scott M, Fearon KC. Enhanced recovery after surgery: a review. JAMA Surg 2017;152:292-298.

9. Vlug MS, Wind J, Hollmann MW, et al. Laparoscopy in combination with fast track multimodal management is the best perioperative strategy in patients undergoing colonic surgery: a randomized clinical trial (LAFA-study). Ann Surg 2011;254:868-875.

10. Gustafsson UO, Oppelstrup H, Thorell A, Nygren J, Ljungqvist O. Adherence to the ERAS protocol is associated with 5-year survival after colorectal cancer surgery: a retrospective cohort study. World J Surg 2016;40:1741-1747.

11. Kang SH, Lee Y, Min SH, et al. Multimodal enhanced recovery after surgery (ERAS) program is the optimal perioperative care in patients undergoing totally laparoscopic distal gastrectomy for gastric cancer: a prospective, randomized, clinical trial. Ann Surg Oncol 2018;25:3231-3238.

12. Gianotti L, Fumagalli Romario U, De Pascale S, et al. Association between compliance to an enhanced recovery protocol and outcome after elective surgery for gastric cancer: results from a Western population-based prospective multicenter study. World J Surg 2019;43:2490-
2498.

13. Hyun KR, Kang S, Lee S. Does long-term care insurance affect the length of stay in hospitals for the elderly in Korea?: a difference-indifference method. BMC Health Serv Res 2014;14:630.

14. Kim JH, Lee SG, Lee KS, Jang SI, Cho KH, Park EC. Impact of health insurance status changes on healthcare utilisation patterns: a longitudinal cohort study in South Korea. BMJ Open 2016;6:e009538.

15. Lin $\mathrm{X}$, Cai $\mathrm{M}$, Tao $\mathrm{H}$, et al. Insurance status, inhospital mortality and length of stay in hospitalised patients in Shanxi, China: a crosssectional study. BMJ Open 2017;7:e015884.

16. Fanning J, Brewer J. Delay of hospital discharge secondary to postoperative fever: is it necessary? J Am Osteopath Assoc 2002;102:660-661.

17. Crompton JG, Crompton PD, Matzinger P. Does atelectasis cause fever after surgery?: putting a damper on dogma. JAMA Surg 2019;154:375-376.

18. Liang W, Li J, Zhang W, et al. Prolonged postoperative ileus in gastric surgery: is there any difference between laparoscopic and open surgery? Cancer Med 2019;8:5515-5523.

19. Huang DD, Zhuang CL, Wang SL, et al. Prediction of prolonged postoperative ileus after radical gastrectomy for gastric cancer: a scoring system obtained from a prospective study. Medicine (Baltimore) 2015;94:e2242.

20. Gonzalez-Ayora S, Pastor C, Guadalajara H, et al. Enhanced recovery care after colorectal surgery in elderly patients: compliance and outcomes of a multicenter study from the Spanish working group on ERAS. Int J Colorectal Dis 2016;31:1625-1631.

21. Millan M. Enhanced recovery after surgery in elderly and high-risk patients. Ann Laparosc Endosc Surg 2020;5:39. 